\title{
A CENTRALIDADE DA INTERDISCIPLINARIDADE NOS ESTUDOS SOBRE AMBIENTE E SOCIEDADE
}

O objetivo é refletir sobre as idéias centrais contidas no livro editado "Idéias para uma sociologia na questão ambiental no Brasil”, que é produto de uma pesquisa com vários alunos de graduação, pós-graduação e coordenada por mim, em que analisamos empírica e teoricamente a constituição do campo ambiental no nível internacional e como houve, no caso brasileiro, a internalização da problemática ambiental nas ciências sociais, livro editado pela Annablume em 2006.

Atualmente, estendemos a mesma reflexão para o nível da América Latina como um todo, iniciando com seis países e, ao mesmo tempo, tentado fazer uma reflexão numa perspectiva interdisciplinar, projeto temático FAPESP, coordenado por mim. Como a questão ambiental é eminentemente interdisciplinar, no caso brasileiro, pode-se verificar que o processo de institucionalização deu-se nesta perspectiva.

O livro é um pouco da história da nossa geração, no caso brasileiro e, portanto, tem forte cunho de subjetividade. No nível internacional, a questão ambiental penetra nas Ciências Sociais como um todo e particularmente na Sociologia, principalmente em alguns países europeus por causa dos acontecimentos de 1968, por conta da contra-cultura. Enfim, todo um caldo de cultura que havia nos anos 60 permitiu que alguns cientistas sociais particularmente alguns cientistas políticos, começassem a refletir sobre essa problemática de forma sistematizada. Num primeiro momento, a produção dos ecologistas radicais, em meados dos anos 60 e já um pouco na década de 70, foi um discurso super macroteórico e um discurso com forte cunho ideológico. Pode-se citar Ivan Illich, Jean Pierre Dupuy, André Gorz, dentre outros cientistas sociais e filósofos que refletiram sobre essa problemática, mas a partir de uma visão bastante dicotômica da relação sociedade civil e Estado. Ou seja, da mesma forma que outros problemas das Ciências Sociais eram trabalhados pelos demais cientistas sociais, os mencionados cientistas sociais especificamente começaram a discutir a problemática ambiental através dessa relação entre Estado e Sociedade Civil. Em primeiro momento, esta questão era vista por conta dos grandes problemas de degradação sócio-ambientais globais e locais, podendo se pensar ou nas suas causas ou nas suas possíveis soluções.

1 Pós-Doutora em Políticas Públicas e Ambiente (Universidade do Texas/EUA), Teoria Social e Ambiente (Universidade de York/INGLATERRA) e Doutora em Ciências Sociais. (UNICAMPCampinas/SP). Bolsista de Produtividade em Pesquisa do CNPq. Professora da UNICAMP-Campinas/SP. E-mail: leilacf@unicamp.br 
Se pudéssemos pensar em algum nível de solução para problemática ambiental, teria que se articular radicalmente a sociedade civil ou teria que haver alguma intervenção normativa e radical do Estado. Entretanto, os ecologistas radicais descentralizadores, citados acima, não problematizavam essa questão do ponto de vista empírico, mas faziam uma reflexão macro teórica sobre ela.

Em 1973, um jovem cientista político, William Ophuls, defendeu uma tese de doutoramento nos EUA e que se tornou, na verdade, um marco na área porque foi a primeira vez que um cientista social buscou no interior da teoria ecológica alguns elementos para pensar a problemática ambiental. Ele se utilizou de conceitos ecológicos como a questão do holismo, da interdependência do sistema, do clima, dentre outros, para problematizar a questão do Estado. Utilizou-se, também, obviamente do clássico da tragédia dos comuns para pensar essa interligação entre a questão do Estado e da Sociedade Civil.

Isso foi em 1973 quando ele defendeu a tese chamada "Ecology in the policy of Scarcity", cujo livro acabou sendo publicado em 1977, no mesmo momento em que Ivan Illich, Jean Pierre Dupuy publicavam, na Europa, uma outra visão sobre a questão ambiental, salientando a importância da sociedade civil para a solução do problema.

Essa citação de alguns autores da década de 1970 tem a intenção de mostrar que naquele momento, no caso internacional, a problemática ainda era vista do ponto de vista da relação dicotômica e antagônica entre a sociedade civil e o Estado.

Nos anos 80, a internalização da problemática começa a se dar no nível do campo científico nos centros de pesquisas, nas universidades, e toda a discussão mais macro teórica que ocorreu por meio dos autores citados como exemplos, começou a ser problematizada no nível de dissertações de mestrado, de teses de doutorado e assim por diante.

Essa produção, essa massa crítica acaba demonstrando que devemos ficar nem tanto ao céu, nem tanto à terra. Em primeiro lugar, mais do que a produção intelectual, porque ela não é um insight divino, mas produto do que acontece na realidade, a própria internalização da questão ambiental, no interior de toda a estrutura social vai mostrando que onde e quando houve minimamente uma busca de algum tipo de solução para a degradação sócio-ambiental e local, foi quando vários autores sociais participaram desse processo.

E isso é muito importante pois começamos a observar a produção dos que denominamos ecologistas moderados, que é exatamente tentar contrapor aos ecologistas radicais a idéia de que uma ação normativa e intervencionista do Estado é a solução para o problema ou, minimamente, a mobilização radical da sociedade civil. Daí vão surgir vários estudos de casos, fantásticos e interessantíssimos muito bem relatados nos anos 80 num livro que também se tornou clássico na área ambiental, de Paelkhe, onde o autor vai contando como a internalização da problemática ocorreu nos Estados Unidos, quando foi se transformando uma visão já científica e acadêmica sobre essa nova problemática.

Então, aquele forte cunho ideológico, que ocorria nos ecologistas radicais e que não se trata, obviamente, de uma produção menos ou mais importante do que a recente, é substituído por uma produção mais empírica, mais 
científica, que acaba fazendo com que o campo ambiental se torne um campo importante e significativo no interior das Ciências Sociais internacionais.

Posto isto, e paralelo a isto - como outros subcampos no interior da sociologia, como a sociologia das comunidades, a das religiões, a rural, a urbana - a sociologia ambiental também surge no caso internacional como uma conseqüência de uma problemática que não foi anteriormente estudada significativamente pelos clássicos e muito pouco estudada pela Teoria Social Contemporânea. Isso muda radicalmente a partir dos anos 80. A Sociologia ambiental a partir de questões específicas, a urbana, das florestas, enfim, de problemas concretos e objetivos vai se tornando se tornando um campo científico relevante em várias partes do mundo e o processo de institucionalização da sociologia ambiental se dá de forma mais radical e forte, em primeiro lugar, nos EUA.

Existem várias hipóteses sobre por que isso ocorreu nos EUA e não em outros lugares. O fato é que a sociologia ambiental acaba sendo um produto de boas idéias, de pessoas inteligentes, competentes, mas acaba, também, sendo produto do processo de institucionalização dessa temática no interior das ciências sociais.

Então, temos instituições como a International Sociological Association, a ISA e outras associações que vão colocando esta temática no interior dos seus grupos de trabalho.

A ISA, em 1991, fundou o grupo RC24, Environment of Society, com um grupo pequeno de intelectuais, mas que acabou, nos anos 90, sendo um dos grupos que tinham maior demanda no interior da ISA.

Esse processo de institucionalização demonstra que já havia uma mas- sa crítica concreta e objetiva tanto nas ciências sociais quanto na sociologia para essa questão. Ao mesmo tempo estamos falando de uma década marcada pelo acidente de Chernobyl, onde a questão ambiental torna-se importante para todos os atores sociais. Ela é a agenda dos governos, dos movimentos sociais, é internalizada no campo científico e assim por diante.

Os grandes cientistas sociais paralelos a essa internalização no subcampo da sociologia ambiental, no interior da Teoria Social, autores extremamente importantes como Habermas, Touraine, Castells, e fundamentalmente Ulrich Beck e Anthony Giddens, colocam essa problemática nas suas reflexões, nos seus estudos.

Um dos autores que é considerado hoje um dos maiores teóricos contemporâneos na área da teoria social, Ulrich Beck, problematizou em seu livro Risk Society (1986) a centralidade da questão ambiental para o entendimento da sociedade complexa. Para ele, o Estatuto da Política e o Estatuto da Ciência são fundamentais do que conceitua como a sua sociedade de risco e, para ele, essa sociedade que esta no nível entre a alta modernidade e a pós-modernidade, ou seja, na contemporaneidade radical, a problemática ambiental é fundamental para o entendimento dessa sociedade complexa.

Assim, no nível internacional, ocorreu a internalização da problemática ambiental no nível do discurso da teoria social contemporânea. Ocorreu, ao mesmo tempo, uma internalização desse subcampo no interior da sociologia chamada de ambiental, um campo super heterogêneo, com várias questões conceituais que os diferenciam internamente.

No caso brasileiro, é muito interessante lembrar o livro de Ianni, sobre 
a Sociologia na América Latina, em que se discute a pouca tradição teórica que temos. Entretanto, temos algumas especificidades concretas e objetivas que possibilitaram, inclusive, que tivéssemos a teoria da dependência, com todas as idiossincrasias que a ela possa ter no interior do campo sociológico, mas foi a concretude da nossa realidade que possibilitou esta teoria. Ou seja, um continente com alta desigualdade social, um continente com uma cultura fantástica, com uma história social muito específica que permite que nós, cientistas sociais, tenhamos um olhar sobre a realidade que nos diferencia dos europeus, dos norte-americanos, só para citar esses dois campos científicos e, no caso brasileiro, é muito interessante porque a nossa história se refere a um país continental, a um país com alta desigualdade social e, ainda, um país com alta biodiversidade.

Mas o que ocorre? Nós latinoamericanos e, particularmente, os brasileiros, podemos olhar a produção internacional e ao mesmo tempo pensarmos o que ela tem a ver com a nossa realidade. Obviamente que todos estamos falando aqui sobre uma sociedade de risco.

Primeiro porque ela era vista como uma questão menor dentre as outras questões do humanismo, como se pudéssemos diferenciar a questão social da questão ambiental. Então, é por isso que essa é uma questão geracional, para os grandes cientistas sociais brasileiros como Ianni, dentre outros, pois não se tratava da questão central da análise do Brasil, por exemplo.

$\mathrm{Na}$ década de 30, os teóricos brasileiros, como o Gilberto Freyre, Sérgio Buarque de Holanda e Caio Prado estudaram a questão nacional. Obviamente que, quando se lê toda a obra de Gilberto Freyre a questão da natureza está presente, mas a questão ambiental não é tratada como os outros temas da cultura, a questão da raça e a nacional em si.

Na década de 60, os autores como Fernando Henrique Cardoso, Octavio Ianni, dentre outros, vão problematizar a questão do desenvolvimento e uma geração posterior vai tentar trabalhar a questão do desenvolvimento vinculada às questões que perpassam o próprio desenvolvimento, e uma delas é a questão ambiental. Por isso, essa questão no Brasil internaliza-se radicalmente a partir dos anos 80 .

É interessante, nesse ponto lembrar que essa questão nasceu no campo científico, no interior de algumas universidades do sul e do sudeste do país e hoje, em menos de 20 anos, podemos observar que ela é tratada no interior das ciências sociais no Brasil como um todo.

Por vezes, temos sociólogos, antropólogos, economistas problematizando essa questão. Outras vezes são dinâmicas de pesquisa em cursos de graduação, pós-graduação, por meio de grupos formados, de professores convidados, enfim, centros literalmente de excelência e de pesquisa problematizando a questão. E isso se dá hoje no Brasil como um todo.

Existem alguns autores, como Hector Leis, que dizem que, do ponto de vista latino-americano e particularmente brasileiro, nós na área ambiental muito mais respondemos a uma demanda desenfreada da sociedade civil em relação à problemática do que já temos uma massa crítica e uma reflexão teórica sobre o tema.

Mas entendemos justamente o contrário. Estamos comprovando tanto no caso brasileiro quanto nos demais países latinoamericanos estudados por mim, que há alguns centros de 
pesquisa com boas reflexões teóricas e pesquisas empíricas muito interessantes. Portanto, hoje podemos dizer que já temos um campo científico, o qual não denominamos mais como sociologia ambiental e, que vai muito além desse subcampo no interior da sociologia, que é o campo da área de ambiente e sociedade e com uma massa crítica de estudantes, professores e pesquisadores. 